\title{
Gas Chromatographic Analysis of the Phyto-Constituents and the Assessment of the Anti-Microbial Properties of the Leave Extracts of Nigeria-Grown Gingko biloba
}

\author{
Ubaoji, K.I. ${ }^{1}$, Nwosu, O.K ${ }^{2}$, Agu, K.C. ${ }^{3}$, Nwozor, K.O. ${ }^{4}$, Ifedilichukwu, N.H. ${ }^{5}$, Okaka, A.N.C. ${ }^{6}$ \\ ${ }^{1}$ Department of Applied Biochemistry, NnamdiAzikiwe University, Awka, Nigeria. \\ ${ }^{2}$ National Biosafety Management Agency, Abuja, Nigeria \\ ${ }^{3}$ Department of Applied Microbiology, Nnamdi Azikiwe University, Awka, Nigeria. \\ ${ }^{4}$ Department of Biochemistry, Federal University of Gusau, Nigeria. \\ ${ }^{5}$ Department of Medical Biotechnology, National Biotechnology Development Agency, Abuja. \\ ${ }^{6}$ Department of Applied Biochemistry, NnamdiAzikiwe University, Awka, Nigeria.
}

\section{Article Info}

Article history:

Received:07 September 2020

Revised: 18 October 2020

Accepted: 22 October 2020

\section{Keywords: \\ Ginkgo biloba, \\ Phytochemicals, \\ Antibacterial, \\ Antifungal, Gas \\ Chromatography, \\ Microorganisms.}

Paper Type :

Research Article

Corresponding Author:

Nwosu, O.K

Email:

nwosuonyeka6@gmail.com

\begin{abstract}
Purpose: Gingko biloba (GB) leaves have been recognized for their therapeutic effects, dating back to traditional Chinese medicine where the ground leaves were used to treat several health problems. GB extracts are renowned for their medicinal properties in Asia, Europe and South America. However, GB leaves are rarely grown and used in Nigeria. In this study, we screened the phytochemical constituents and antimicrobial activities of $G B$ leaves (aqueous and ethanol extracts) grown in Enugu, Enugu State, South East Nigeria.

Study Design: Experimental

Materials and Methods: Quantitative analyses of phytochemicals were done using gas chromatography while disk diffusion and broth dilution methods were used to determine the antimicrobial activities.

Results: The phytochemical analysis of aqueous and ethanol extracts showed high quantity of flavonoids (anthocyanin, rutin, epicatechin, kaemferol and catechin), alkaloids (lunamarine and ribalindine) and saponin while the moderate quantity of steroids and terpenes, tannin and phenols were also observed. The phytochemical analysis also showed very little concentration of antinutrients (phytate and oxalate) in both extracts. The ethanol extract showed some degree of antibacterial and antifungal activities as observed from their zones of inhibition (mm). Activity was observed on gram-positive bacteria; Staphylococcusaureus $(15.5+0.71 \mathrm{~mm})$ and less activity on gram-negative bacteria; Escherichia coli $(10.5+1.41 \mathrm{~mm})$ and Pseudomonasaeruginosa (no activity). Also there was an activity on yeast; Candida albicans $(16.5+0.71 \mathrm{~mm})$ and less activity on moulds; Penicilliumcyclopium $(9+1.41 \mathrm{~mm})$ and Aspergillus fumigatus (no activity). The aqueous extract showed no antimicrobial activity on both bacteria and fungi.

Conclusion: This study revealed the medicinal potentials of Ginkgo biloba leaves grown in Nigeria. The findings, therefore, will be useful for pharmaceutical industries and medical practice in Nigeria and beyond for the provision of good health to individuals.
\end{abstract}

\section{Introduction}

For many years, plants have been used as medicine because they are an important source of many biologically and therapeutically active products. These plants have been 
implicated in the treatment of several ailments but some of them may have undesirable effects in the body. Even though medicinal plants have provided biologically relevant products for centuries, they still serve as a source for new medicines, thereby increasing the global interest in ethnopharmacological studies (Damery et al., 2011). The increasing motivation for these ethnopharmacological studies in recent times is based on how traditional healers (herbalists) use plants therapeutically. The essence of such studies is to identify or discover interesting properties and constituents of plants that make them therapeutic or medicinal. The medicinal properties of the plants are mainly attributed to the presence of various simple and complex organic compounds in them (Raaman, 2008). These compounds are called secondary metabolites. It is due to these compounds that many medicinal plants are said to be therapeutic including being anti-microbial.

These secondary metabolites are non-essential nutrients in such that they are not required by animal for sustaining life (Raaman, 2008). Unlike primary metabolites, the absence of secondary metabolites does not result in immediate death, but in the long-term impairment of the organism's survival/fecundity or aesthetics or, perhaps, in no significant change at all (Kennedy \& Whightman, 2011). The common secondary metabolites usually obtained from plants are flavonoids, alkaloids, anthraquinone, cardiac glycoside, phenols, terpenes, steroids, saponin, tannin, reducing sugar and pyrolizidine (Dillard \& German, 2000).

Microbes or microorganisms are microscopic living organisms that are single-celled or multicellular. Many of these microbes are especially dangerous for the very young, frail elderly, immun-compromised or critically ill individuals, as well as patients with particular physiological or dermatological disorders (Jayaprakash et al., 2003). Notably, healthy individuals are also at risk, and this is most clearly evident in less affluent regions in the world like Nigeria, where infectious diseases are still a major cause of morbidity and mortality. Antimicrobials are all agents (including plant parts) that act against all types of microorganisms- bacterial (antibacterial), fungi (antifungal), viruses (antiviral) and protozoa (antiprotozoal). These antimicrobials according to Peach et al. (2013) have different modes of action, owing to the nature of their structure and degree of affinity to certain target sites. They include inhibitors of cell wall synthesis, inhibitors of cell membrane functions, inhibitors of protein synthesis and inhibitors of nucleic acid synthesis among others.

An ancient Chinese tree that had appeared more than 250 million years ago, and the only surviving member of Ginkgoaceae family; Ginkgo biloba, has been used extensively by traditional and visionary healers around the world, especially Asia and South America due to its acclaimed therapeutic functions (DeFeudis, 1998). The leaves of Ginkgo biloba tree have attracted attention as agents for improving circulation, particularly cerebral circulation which may lead to improved mental functions (Wadsworth \& Koop, 2001). Kwon et al. (2004) reported that Gingko biloba leaf extracts have been implicated in the treatment of poor circulation, impotence, heart diseases, eye diseases, chronic cerebral insufficiency, short term memory loss (like Alzheimar's diseases), depression and dementia. This paper is designed to analyze the phytochemical constituents and determine the anti-microbial properties of Nigerian grown Gingko biloba leaves (aqueous and ethanol extract). 


\section{Methodology and Procedures}

\section{Collection and Extraction of Plant Leaves}

Healthy fresh leaves of Ginkgo biloba were collected from Ginkgo biloba tree at Park Avenue, GRA, Enugu, Enugu State, Nigeria in a large quantity. The plant was identified and authenticated by a plant taxonomist in the Botany Department of Nnamdi Azikiwe University, Awka. The voucher specimen was deposited in the Hebarium of the Department. The leaves were dried at room temperature for three weeks. The dried leaves were later ground into a fine powder using a local steel grinder. To obtain an aqueous extract, $30 \mathrm{~g}$ of the ground leaves was mixed with $300 \mathrm{ml}$ of distilled water. Then $30 \mathrm{~g}$ of the ground leaves was mixed with $80 \%(\mathrm{v} / \mathrm{v})$ ethanol to obtain an ethanol extract. Both mixtures were refluxed in a water bath at $65^{\circ} \mathrm{C}$ for 1 hour and filtered using Whitman filter paper No. 1 followed by the evaporation of the filtrate to slurry form using a rotary evaporator.

\section{Phytochemical Quantification}

Quantification of the phytochemical constituents in the aqueous and ethanol extracts was done using gas chromatography, fitted with flame ionization detector (GC-FID) employing Martin and Synge (1941) method and modified by Ujowundu et al. (2015).

\section{Procedure:}

For each extract, $0.5 \mathrm{ml}$ was introduced into separating funnels containing $0.5 \mathrm{~g}$ of sodium sulphate. Then $20 \mathrm{ml}$ of $\mathrm{N}$-hexane was added to each column and was left to stand for a few minutes after which the N-hexane layer was extracted and used for the GC-FID analysis.

\section{Conditions for the Quantification:}

The quantification of the phytochemicals was performed on a BUCK M910 Gas Chromatograph equipped with a flame ionization detector. A RESTEK 15 meter MXT-1 column $(15 \times 250 \times 0.15 \mu \mathrm{m})$ was used. The injector temperature was $280^{\circ} \mathrm{C}$ with a splitless injection of $2 \mu 1$ of the sample and a linear velocity of $30 \mathrm{cms}^{-1}$. Helium $5.0_{\text {pass }}$ was the carrier gas with a flow rate of $40 \mathrm{mlmin}^{-1}$. The oven operated initially at $200^{\circ} \mathrm{C}$, it was heated to $330^{\circ} \mathrm{C}$ at a rate of $3^{0} \mathrm{C} \mathrm{min}^{-1}$ and was kept at this temperature for 5 minutes. The detector operated at a temperature of $320^{\circ} \mathrm{C}$.

The phytochemicals were then determined by the ratio between the area and mass of internal standards and the area of the identified phytochemicals. The concentration of the different phytochemicals was expressed in $\mu \mathrm{g} / \mathrm{ml}$.

\section{Antimicrobial Analysis}

\section{Test Organisms:}

A total of three pathogenic bacteria namely: Escherichia coli, Staphylococcus aureus, Pseudomonas aeruginosa and three pathogenic fungi, Candida albicansAspergillusfumigatus, 
Penicilliumcyclopium were obtained from the Reference Laboratory section of the Department of Applied Microbiology and Brewing, NnamdiAzikiwe University Awka, Anambra State, Nigeria. These organisms were maintained on Nutrient Broth for Bacteria and Sabouraud Dextrose Broth for fungi.

\section{Antimicrobial Susceptibility Test:}

This was determined by the modified method described by Agu et al. (2013). Plates that had confluent and/or semi-confluent growth were selected for the antimicrobial susceptibility tests. The disk diffusion method was used to assay the effect of the extracts on the various microorganisms. Mueller-Hinton Agar was used for the bacteria and Sabouraud Dextrose Agar (SDA) for the fungus. Twenty four hours broth cultures of the test organisms were serially diluted, then $10^{-1}$ and $10^{-2}$ dilutions were used to seed the fungal isolates, while $10^{-2}$ was used to seed the bacterial plates. Then $0.1 \mathrm{ml}$ of the appropriate dilution of the broth culture of each microorganism was uniformly spread using a sterile glass spreader on the surface of the media, and sterile filter papers were soaked in the neat Ginkgo biloba extracts (aqueous and ethanol) that is in slurry form and placed on two points on each petri dish. Incubation was done at room temperature for 24 hours for bacteria and 48 hours for fungi. Clear zones of inhibition around the wells indicated antimicrobial activities of the extracts against the test organisms. The diameters of the zones of inhibition were measured and recorded in millimetres. Negative controls were set up with sterile water and positive controls were set up using $0.5 \%$ Nystatin for fungi and $0.5 \%$ Ciprofloxacin for bacteria.

\section{Determination of Minimum Inhibitory Concentration (MIC):}

The Modified method of Pallotaet al. (2007) was used for this study. The Minimum Inhibitory Concentration (MIC) was determined by the broth dilution method. Different test tubes containing Nutrient Broth (bacteria) and Sabouraud Dextrose Broth (fungi), which contained $20 \%, 40 \%, 60 \%$ and $80 \%$, of the extracts were inoculated with known amounts of the bacterial and fungal isolates, with a dilution factor of $10^{-2}$ for bacteria and $10^{-1}$ and $10^{-2}$ for fungi and controls (negative and positive) were set up also. The plates were incubated at room temperature for 24 hours for both bacteria and fungi in a metabolic rotary shaker (220 revs/min). Thereafter, the incubated test tubes were then sub-cultured onto sterile freshly prepared plates and incubated for 24 hours for bacteria and 48 hours for fungi. At the end of the incubation period, the plates were counted and the total microbial count recorded in $\mathrm{CFU} / \mathrm{ml}$. The plate with the lowest count was recorded as the MIC. The MIC is defined as the lowest concentration required to arrest the growth of the micro-organism at the end of $24 \mathrm{~h}$ or $48 \mathrm{~h}$ of incubation.

\section{Results and Discussion}

Some data obtained in this study were evaluated using the Statistical Package for Social Sciences (SPSS). The values were expressed as a mean of duplicate determination \pm standard deviation. Analysis of variance (ANOVA) was done at 0.05 level of significance, if $\mathrm{P}<0.05$, there is a significant difference. 
Table 1: GC-FID Quantitative Analysis of Phytochemical Compositions of Aqueous Extract of Ginkgo biloba leaf

\begin{tabular}{lllll}
\hline Components & Subclass & $\begin{array}{l}\text { Concentration } \\
(\mu \mathrm{g} / \mathrm{ml})\end{array}$ & \% Concentration & $\begin{array}{l}\text { Retention time } \\
(\mathrm{mins})\end{array}$ \\
\hline Flavonoids & Anthocyanin & 0.745 & 0.455 & 1.883 \\
& Rutin & 27.651 & 16.871 & 8.750 \\
& Epicatechin & 3.674 & 2.242 & 15.696 \\
& Kaempferol & 45.474 & 27.746 & 39.246 \\
& Catechin & 0.858 & 0.523 & 45.253 \\
Total & & & 47.837 & \\
Alkaloids & & & & \\
& Lunamarine & 26.669 & 16.272 & 18.260 \\
Total & Ribalinidine & 1.661 & 1.013 & 31.460 \\
Steroids and & & & 17.285 & \\
Terpenes & & & & \\
Saponin & Sapogenin & 19.859 & 12.117 & 29.116 \\
Tannin & & 21.316 & 13.006 & 24.106 \\
Phenol & & 7.986 & 4.873 & 4.766 \\
Phytate & & 7.416 & 4.525 & 12.666 \\
& & 0.586 & 0.358 & 32.336 \\
\hline
\end{tabular}

Source: Authors

Table 2: GC-FID Quantitative Analysis of Phytochemical Compositions of Ethanol Extract of Ginkgo biloba leaf

\begin{tabular}{lllll}
\hline Components & Subclass & $\begin{array}{l}\text { Concentration } \\
(\mu \mathrm{g} / \mathrm{ml})\end{array}$ & \% Concentration & $\begin{array}{l}\text { Retention time } \\
(\mathrm{mins})\end{array}$ \\
\hline Flavonoids & Anthocyanin & 0.746 & 0.369 & 1.883 \\
& Rutin & 27.660 & 13.682 & 8.750 \\
& Epicatechin & 3.685 & 1.823 & 15.696 \\
& Kaempferol & 45.457 & 22.486 & 39.246 \\
& Catechin & 41.482 & 20.519 & 45.350 \\
Total & & & 58.879 & \\
Alkaloids & & & & \\
& Lunamarine & 26.775 & 13.244 & 18.260 \\
& Ribalinidine & 1.661 & 0.916 & 31.413 \\
Total & & 14.160 & \\
Steroids and & & & & \\
Terpenes & & & & \\
\hline
\end{tabular}

Copyright (C 2020, Journal of Scientific Research in Medical and Biological Sciences (JSRMBS), Under 


\begin{tabular}{|c|c|c|c|c|}
\hline & Sapogenin & 20.004 & 9.895 & 29.116 \\
\hline Saponin & & 21.334 & 10.553 & 24.106 \\
\hline Tannin & & 4.529 & 2.240 & 4.903 \\
\hline Phenol & & 7.430 & 3.675 & 12.666 \\
\hline Oxalate & & 0.650 & 0.322 & 4.596 \\
\hline Phytate & & 0.555 & 0.275 & 32.353 \\
\hline
\end{tabular}

Source: Authors

Table 3 Antibacterial Susceptibility Screening of Ginkgo biloba leaf Extracts

Zone of Inhibition (mm)

Isolates Aqueous Extract Ethanol Extract Positive Control

Staphylococcusaureus

$15.5 \pm 0.71 *$

$39 \pm 1.41$

Escherichia coli

$10.5 \pm 0.71^{*}$

$26 \pm 2.12$

Pseudomonas aeruginosa

Data are the means of duplicate determination \pm standard deviation. The positivecontrol is

Ciprofloxacin. The negative control used was sterile water which showed no inhibition. ${ }^{*}<0.05$ when compared with positive control.

Source: Authors

Table 4 Antifungal Susceptibility Screening of Ginkgo biloba leaf Extracts

\begin{tabular}{lccc}
\hline & \multicolumn{3}{c}{ Zone of Inhibition (mm) } \\
Isolates & Aqueous Extract & Ethanol Extract & Positive Control \\
& & & \\
\hline Aspergillus fumigatus & - & $16.5+0.71^{*}$ & $41+1.41$ \\
Candida albicans & - & - & $34.5+2.12$ \\
Penicilliumcyclopium & - & $9+1.41^{*}$ & $36.5+2.12$ \\
\hline
\end{tabular}

Copyright (C) 2020, Journal of Scientific Research in Medical and Biological Sciences (JSRMBS), Under 
Data are the means of duplicate determination \pm standard deviation.The positive control is Nystatin.

The negative control used was sterile water which showed no inhibition. ${ }^{*} p<0.05$ when compared with positive control.

Source: Authors

Table 5 Minimal Inhibitory Concentration (MIC) (\%) of the Ethanol Extract of Ginkgo biloba leaf on the Test Bacteria

\begin{tabular}{|c|c|c|c|c|}
\hline \multirow[b]{2}{*}{ Isolates } & \multicolumn{4}{|c|}{ Colony Count After 24 hours(mm) } \\
\hline & $20 \%$ Conc & $40 \%$ Conc & $60 \%$ Conc & $80 \%$ Conc \\
\hline \multicolumn{5}{|c|}{ Ethanol Extract } \\
\hline & $20 \pm 2.83$ & $\mathrm{NC}$ & $\mathrm{NC}$ & $\mathrm{NC}$ \\
\hline \multicolumn{5}{|c|}{ Staphylococcusaureus } \\
\hline \multicolumn{5}{|c|}{ Positive Control } \\
\hline & $3 \pm 0.00$ & $\mathrm{NC}$ & $\mathrm{NC}$ & $\mathrm{NC}$ \\
\hline \multicolumn{5}{|c|}{ Ethanol Extract } \\
\hline & $16 \pm 2.83$ & $5 \pm 0.00$ & $2 \pm 0.00$ & $1 \pm 0.00$ \\
\hline Escherichia coli & \multicolumn{4}{|c|}{ Positive Control } \\
\hline & $12 \pm 1.41$ & $\mathrm{NC}$ & $\mathrm{NC}$ & $\mathrm{NC}$ \\
\hline
\end{tabular}

Data are the means of duplicate determination \pm Standard deviation. The positive control is

Ciprofloxacin. The negative control used was sterile water which showed no inhibition. $N C=N o$ count.

Source: Authors

Table 6: Minimal Inhibitory Concentration (MIC) (\%) of the Ethanol Extract of Ginkgo biloba leaf on the Test Fungi

Colony Count After 48 hours (mm)

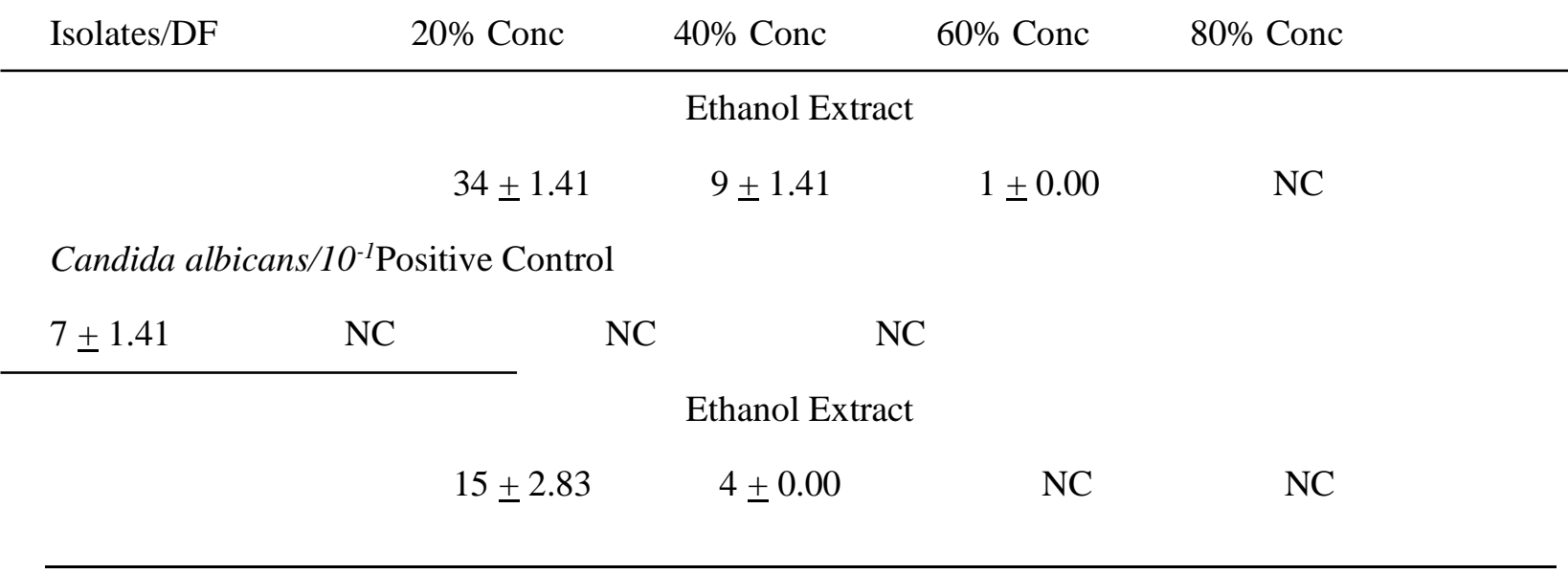

Copyright (C) 2020, Journal of Scientific Research in Medical and Biological Sciences (JSRMBS), Under 
Candida albicans $/ 10^{-2}$ Positive Control

$$
4 \pm 1.41 \quad \mathrm{NC} \quad \mathrm{NCNC}
$$

Ethanol Extract

$$
14 \pm 1.41 \quad 3 \pm 1.41 \quad \mathrm{NC} \quad \mathrm{NC}
$$

Penicilliumcyclopium $/ 10^{-1}$ Positive Control

$\mathrm{NC} \quad \mathrm{NCNCNC}$

Ethanol Extract

$$
7 \pm 1.41 \quad 2 \pm 0.00 \quad \mathrm{NC} \quad \mathrm{NC}
$$

Penicilliumcyclopium/10-2Positive Control

$\mathrm{NC}$

NCNCNC

Data are means of duplicate determination \pm Standard deviation. Positive control is Nystatin. The negative control used was sterile water which showed no inhibition. DF $=$ Dilution factor, NC $=$ No count.

Source: Authors

\section{Discussion}

In this study, gas chromatography linked with flame ionization detector (GC-FID) showed the quantities of 12 and 13 specific phytochemicals in the aqueous and ethanol extracts respectively, as seen in tables 1 and 2 . The identification of these specific phytochemicals was done by comparison of the GC- retention time of the standard phytochemicals which was saved in the data system library. Flavonoids content was observed to be in the highest quantity in both extracts considering the concentration levels of the different components of flavonoids like epicatechin, kaempferol, anthocyanin, catechin and rutin. Catechins have shown to possess antibiotic properties due to their role in disrupting a specific stage of the bacterial DNA replication process (Gradisar et al., 2007). It may have contributed immensely to the many reported antibacterial effects of the leaf. Rutin has been reported to have clinically relevant functions that include anti-inflammatory, antihaemorrhagic activity and strengthening of capillary permeability and stabilization of platelets (Guo and Wei, 2008).Kaempferol and anthocyanin are antioxidant components and could have aided in the massive reports of the antioxidant properties of the leaves. Anthocyanin has been reported to be involved in the improvement of vision, decreased platelet aggregation and neuroprotective effects (Tyagi et al., 2010). The specific alkaloid; lunamarine has shown to be immunomodulatory and anti-amoebic activity, particularly against Entamoeba histolytica. Alghabban (2014) in his study confirmed that the Ginkgo biloba leaf extract inhibited and treated Entamoeba histolytica infection. Tannin was also identified as shown in Table 1 and 2 for aqueous and ethanol extracts. Tannin has been reported to be an essential antioxidant, antimicrobial and anti-cancer activities (Dillard and German, 2000). Saponin content in aqueous and ethanol extracts is quite significant with concentrations of $21.3164 \mu \mathrm{g} / \mathrm{ml}$ and $21.3336 \mu \mathrm{g} / \mathrm{ml}$ respectively. The saponins are generally 
known to exert hypoglycaemic and anticholesterol effect through intra-lumenal physiochemical interactions (Price et al., 1987). Saponin has also been implicated to act as antibacterial agents (Lacaille-Dubois \& Wagner, 2000).

This study as with many other studies on Ginkgo biloba had indicated the high content of phenols in the leaf and had contributed immensely with steroids and terpenes (sapogenin) and flavonoids to its highly recognized antioxidant effect. The study also identified very low content of anti-nutrients (oxalate and phytate) in both extracts which are very good for consumption. The study has shown that the extracts contain appreciable phytochemicals that exact many therapeutic functions, it can be said that the extracts may be safe for human consumption for medicinal purposes. However, it is pertinent to state that the percentage of each constituent in the extracts can vary according to the country where it was grown and the season in which the plant leaves were harvested (Sati et al., 2013).

Table 3 and 4 showed that the aqueous extract did not show any antibacterial and antifungal activity on the three bacteria and fungi. Ethanol may be a better solvent for the extraction of the secondary metabolites from the leaves especially catechin, as shown in comparison between table 1 and 2. Catechin may have being the leaf's constituent that easily diffused into the bacterial and fungal cell wall. The reason for the reduced effect of the extracts on gram-negative bacteria and mould may have been due to the complexity of the cell wall of gram-negative bacteria and the central core of the mould cell wall that is a branched $\beta 1,3,1,6$ glucan linked to chitin via $\beta$ 1, 4 linkage (Latge, 2007) respectively. Majorly, $\beta$ 1, 3 glucan synthase inhibitors is used clinically to target Aspergillusfumigatus and other mould fungi (Latge, 2007). This result is in consonance with Sati and Joshi (2011) who confirmed the antibacterial effect of Ginkgo biloba ethanol extract of Indian origin on many bacteria including Escherichia coli that showed low inhibition. The result is also in consonance to those of Sati et al., (2012) who confirmed that the aqueous leaf extract of Ginkgo biloba from India did not show any activity on gram-negative and gram-positive bacteria, and mould and yeast whereas other extracts including ethanol showed antibacterial and antifungal effect.

In table 5, the colony count was high in $20 \%$ dilution of the Ginkgo biloba ethanol extract for Staphylococcus aureus and Escherichia coli. This is due to the low concentration of the extract, however 40\%, 60\% and $80 \%$ concentrations for Staphylococcus aureus showed no colony count indicating that $40 \%$ dilution $(0.4 \mathrm{ml}$ of extract in $0.6 \mathrm{ml}$ of broth) extract may have been able to inhibit and kill Staphylococcus aureus. As for the E.coli, 40\%, $60 \%$ and $80 \%$ dilution concentration of the extract showed a decrease in the colony count in that sequential order. Therefore it can be said that at $40 \%$ dilution concentration, the extract may inhibit E.coli to the greatest minimum, and at $80 \%$ dilution concentration, the extract may kill E.coli.

In table 6 , the colony count was high in $20 \%$ of $10^{-1}$ dilution factor with $34 \pm 1.41$ count and $20 \%$ of $10^{-2}$ dilution factor with $15 \pm 2.83$ count of Candida albicans. This is due to the low concentration of the extract while $40 \%$ and $60 \%$ concentration for $10^{-1}$ dilution factor; the count decreased showing greater inhibition on Candida albicans. The $80 \%$ concentration of the extract may be able to kill Candida albicans. It was the same for $10^{-2}$ dilution factor with $60 \%$ concentration that may be able to inhibit and kill Candida albicans. 
The same inhibition based on concentration was observed in Penicilliumcyclopiumas in Candida albicans. However, at $60 \%$ concentration of the ethanol extract, it was able to inhibit and kill Penicilliumcyclopium at $10^{-1}$ and $10^{-2}$ dilution factors.

The inhibition activity of the ethanol extract of Ginkgo biloba leaf signifies the leaf antimicrobial effect and this might be due to presence of variety of active compounds in the extract such as tannin, saponin, alkaloids and flavonoids as suggested by Abo et al., (2000). This study had established the potential of using Ginkgo biloba ethanol leaf extract of Nigerian origin for microbial treatment.

\section{Conclusion and Suggestion}

In conclusion, this study revealed that aqueous and ethanol leaf extracts of Ginkgo biloba from Nigeria possess phyto-constituents of health importance and have shown to possess antibacterial and antifungal properties. The importance of natural products with phyto-constituents of health implication and antimicrobial properties cannot be overemphasized; therefore greater awareness should be vigorously pursued to effectively appropriate the rich chemical constituents and anti-microbial properties of Ginkgo biloba found in Nigeria.

\section{Conflict of Interest}

The authors of the article declare no conflict of interest.

\section{Funding:}

The authors received no funding for conducting this study.

\section{References}

Abo, K,A, Adeyemi, A.A and Jegede, I.A. (2000). Spectrophotometric Estimation of Anthoquinone Content and Antimicrobial Potential of Extracts of some Cassia Species Used in Herbal Medicine in Ibadan. Science Forum,3(2): 57-63.

Agu, K.C., Igweoha, C.A and Umeh, C.N. (2013).Antimicrobial Activity of the Ethanolic and Petroleum Ether Extracts of Tangerine Seed on Selected Bacteria.International Journal of Agriculture and Bioscience, 2(1): 22-24.

Alghabban, A.J.M (2014). Ginkgo biloba Leaf Extract Inhibits and Treated Entamoeba histolytica Infection. Nature and Science, 12(2): 63-68.

Damery, S., Gratus, C and Grieve, R. (2011). The Use of Herbal Medicine by People with Cancer: A Cross Sectional Survey. British Journal on Cancer, 104(6): 927-933.

Defeudis, F.V. (1998). Ginkgo biloba Extract (EGb761), From Chemistry to Clinic.Ullstein Medical, USA

Dillard, C.J and German, J.B. (2000). Phytochemicals: Nutraceuticals and Human Health. Journal of Science of Food and Agriculture, 80: 1744-1756. 
Gradisar, H., Pristovsek, P., Plaper, A and Jerala, R. (2007). Green Tea Catechins Inhibit Bacterial DNA Gyrase by Interaction with its ATP Binding Site. Journal of Medicinal Chemistry,50: 264-271.

Guo, R and Wei, P. (2008).Studies on the Antioxidant Effect of Rutin in the Microenvironment of Cationic Micelles.Microbiology Acta, 161: 233-239.

Jayaprakash, G.K., Selvi, T and Sakariah, K. (2003).Antimicrobial and Antioxidant Activities of Grape (VitisVinifera) Seed Extracts.Food Research International,36: 117-122.

Kennedy, D.O and Whightman, E.C. (2011). Herbal Extracts and Phytochemicals: Plant Secondary Metabolites and Enhancement of Human Brain Function. Advances in Nutrition, 2: 32-50.

Kwon, Y.S., Ann, H.S., Nabeshima, T., Shin, E.J., Kim, W.K and Jhoo J.H. (2004). Selegiline Potentiates the Effects of EGb 761 in Response to Ischemic Brain Injury. Neurochemistry International Journal,45:157-170.

Lacaille-Dubois, M.A and Wagner, H. (2000). Bioactive Saponin from Plants: An Update. Studies in Natural Product Chemistry, Atta-ur-Rahman ed. Elsevier Science, 21: 633687.

Latge, J.P. (2007). The Cell Wall: A Carbohydrate Armour for Fungal Cell. Molecular Microbiology, 66(2): 279-290.

Martin, A.J.P and Synge, R.L.M. (1941).A New Form of Chromatogram Employing Two Liquid Phases.Journal of Biochemistry, 35: 1358-1560.

Pallota, R.C, Ribeiro, M.S and De lima Machado, M.E. (2007). Determination of the Minimal Inhibitory Concentration of Four Medicaments Used as Intracanal Medication.Australian Endodontics Journal,33: 107-111.

Peach, K.C., Bray, W.M., Winslow, D., Linington, P.F and Linington R.G. (2013).Mechanism of Action-Based Classification of Antibiotics Using High-Content Bacterial Image Analysis.Molecular Biosystems,9(7): 1837-1848.

Price, K.R., Johnson, I.Jand Frenwick, G.R. (1987). The Chemistry and Biological Significance of Saponnin in Foods and Feeding Stuffs.Critical Review of Food Science and Nutrition, 26: 633-87

Raaman, N. (2008). Phytochemical Techniques.New India Publishing Agency, New-Delhi, India. Pp 1-9.

Sati, P., Pandey, A., Rawat, S and Rani, A. (2013).Phytochemicals and Antioxidants in Leaf Extracts of Gingko biloba with Reference to Location, Seasonal Variation and Solvent System.Journal of Pharmacy Research,7: 804-809

Sati, P., Pandey, A and Palni, L.M.S. (2012).Antimicrobial Potential of Leaf Extracts of Ginkgo biloba L. Growing in Uttarakhans, India.National Academy of Science Letters, 35(3): 201-206.

Sati, S.C and Joshi, S. (2011). Antibacterial Activities of Ginkgo biloba L. Extracts.Scientific World Journal, 11: 2337-2242.

Tyagi, E., Agrawal, R., Nath, C and Shukla, R. (2010).Cholinergic Protection via Alpha 7 Nicotinic Acetylcholinergic Receptors and P13K-AKT Pathway in LPS-induced Neuroinflammation.Neurochemistry International, 56: 135-142. 
Ujowundu, F.N., Ukoha, A.I., Ojiako, A.O and Nwaoguikpe, R.N. (2015).Isolation of Bioactive Phytochemicals in Leaves of Combretumdolichopentalum and their Hydrogen Peroxide Scavenging Potentials.PharmaceuticaAnalyticaActa Journal,6:435-444.

Wadsworth, T.I and Koop, D.R. (2001).Effects of Ginkgo biloba Extract (EGb 761) and Quercetin on Lipopolysaccharide-Induced Release of Nitric Oxide.ChemicoBiological Interaction, 137: 43-58. 